\title{
Evaluation of the reporting quality of clinical practice guidelines on pancreatic cancer using the RIGHT checklist
}

\author{
Qiwen Zhang ${ }^{1,2}$, Jingli Lu ${ }^{1,2}$, Mengmeng Jia ${ }^{1,2}$, Yanfang $\mathrm{Ma}^{3}$, Mingyang Sun ${ }^{1,2}$, Xiaoxu Chen ${ }^{1,2}$, \\ Xiaohua Ma ${ }^{1,2}$, Yongjie Yang ${ }^{1,2}$, Jian Kang ${ }^{1,2}$, Xiaojian Zhang ${ }^{1,2}$, Salvatore Paiella ${ }^{4}$, Matthew H. G. Katz ${ }^{5}$, \\ Kunihiro Tsuchida ${ }^{6}$, Mark Schattner ${ }^{7}$, Shuzhang Du ${ }^{1,2}$
}

${ }^{1}$ Department of Pharmacy, the First Affiliated Hospital of Zhengzhou University, Zhengzhou, China; ${ }^{2}$ Henan Key Laboratory of Precision Clinical Pharmacy, Zhengzhou University, Zhengzhou, China; ${ }^{3}$ School of Chinese Medicine of Hong Kong Baptist University, Hong Kong, China; ${ }^{4}$ General and Pancreatic Surgery Unit, Pancreas Institute, University of Verona, Policlinico GB Rossi Hospital, Verona, Italy; ${ }^{5}$ Department of Surgical Oncology, the University of Texas MD Anderson Cancer Center, Houston, Texas, USA; ${ }^{6}$ Division for Therapies Against Intractable Diseases, Institute for Comprehensive Medical Science (ICMS), Fujita Health University, Toyoake, Aichi, Japan; ${ }^{7}$ Memorial Sloan-Kettering Cancer Center, New York, NY, USA

Contributions: (I) Conception and design: S Du, Q Zhang; (II) Administrative support: X Zhang, J Kang; (III) Provision of study materials: M Jia, Y Ma, M Sun; (IV) Collection and assembly of data: X Chen, X Ma, Y Yang; (V) Data analysis and interpretation: J Lu, S Paiella, MHG Katz, K Tsuchida, M Schattner; (VI) Manuscript writing: All authors; (VII) Final approval of manuscript: All authors.

Correspondence to: Shuzhang Du. Department of Pharmacy, the First Affiliated Hospital of Zhengzhou University, No. 1 Jianshe East Road, Zhengzhou 450052, China. Email: dushuzhang911@163.com.

Background: The International Reporting Items for Practice Guidelines in Health Care (RIGHT) statement is a set of recommendations for the reporting in clinical practice guidelines (CPGs). We aimed to assess the reporting quality of CPGs for pancreatic cancer following the RIGHT checklist.

Methods: Guidelines for pancreatic cancer were identified by searching electronic databases, guideline databases, and medical society websites. The reporting quality was evaluated by calculating the adherence to the items of the RIGHT checklist and summarizing them over the seven domains and the entire checklist. We also present results stratified by selected characteristics.

Results: A total of 22 guidelines were found eligible. Mean overall adherence to the RIGHT items was $60.0 \%$. All guidelines adhered to the RIGHT items 3, 7a, 13a, while no guidelines reported the items $14 \mathrm{c}$ or $18 \mathrm{~b}$, which are some of the topics dealing with rationale for recommendations and funding source, respectively. Of the seven domains of the RIGHT checklist, "Review and quality assurance" and "Funding and declaration and management of interests" had the lowest reporting rates (25.0\% and $43.2 \%$, respectively); the remaining five domains had reporting rates $>50 \%$. CPGs that reported funding support, were published in higher-impact journals, and that applied a grading system for the quality of evidence, tended to have higher reporting rates.

Conclusions: Our results show that reporting quality of pancreatic cancer CPGs still needs to be improved. The use of the RIGHT statement should be encouraged when developing new guidelines.

Keywords: Pancreatic cancer; clinical practice guidelines (CPGs); International Reporting Items for Practice Guidelines in Health Care checklist (RIGHT checklist); reporting quality

Submitted Mar 05, 2021. Accepted for publication Jun 11, 2021.

doi: 10.21037/atm-21-2644

View this article at: https://dx.doi.org/10.21037/atm-21-2644 


\section{Introduction}

Pancreatic cancer is a highly lethal disease, over 430,000 deaths- $4.5 \%$ of all cancer-related deaths-in 2018 worldwide (1). The current five-year survival rate for pancreatic cancer has increased from $2.5 \%$ in the $1970 \mathrm{~s}$ to $10.5 \%$ in 2017 , representing a modest improvement in survival when compared with other cancers reported in the SEER database (2). Because of nonspecific symptoms, approximately $80 \%$ of patients are typically diagnosed at advanced stage, when surgical resection is no longer likely to be beneficial $(3,4)$. At present, the most accepted therapeutic approach for advanced disease is conventional cytotoxic chemotherapy, providing only months of additional survival benefit (5).

Although clinical progress has been slow, the sequencing of cancer genomes has advanced our understanding of the biology of pancreatic cancer. The complexity of the genome indicates that pancreatic cancer is a heterogeneous disease and individualized therapy is required (6). As a consequence, new potentially practice-changing evidence is emerging, such as the addition of pembrolizumab as an option for mismatch repair-deficient or microsatellite instabilityhigh tumors (7), and targeted therapy for $B R C A$ mutation or NTRK fusions (8). In addition, palliative and supportive care, follow-up after treatment, and the management of adverse events need better consideration (9). Of note, the existing evidence regarding these novel therapies is still limited in terms of the number of studies and sample size.

Many clinical practice guidelines (CPGs) have been published to address these issues, balance the benefits and harms, and assist clinicians individualize clinical decision making for patients with pancreatic cancer. As the number of guidelines increases, concerns have risen about their reliability, which may be affected by the validity of the recommendations and the quality in reporting and methodology. Explicit reporting of the methods and procedures ensures high quality of guidelines, which in turn leads to reliable recommendations (10). Thus, the quality of CPGs should be reviewed critically before recommendations are implemented into clinical practice.

Several instruments have been developed to assess the quality of CPGs. Among them, the International Reporting Items for Practice Guidelines in Health Care (RIGHT) checklist focuses on guideline reporting. The tool contains seven domains (11). RIGHT was published in 2016, and has been widely accepted for the reporting quality assessment of guidelines. To our knowledge, the reporting quality of CPGs for pancreatic cancer has not yet been assessed. Therefore, we aimed to identify guidelines for pancreatic cancer published in the past three years and use the RIGHT tool to critically evaluate their reporting quality. This study provides data for guideline developers to improve their guideline reporting process for pancreatic cancer.

\section{Methods}

\section{Study design}

We conducted a critical appraisal of the reporting quality of CPGs for pancreatic cancer using the RIGHT checklist.

\section{Literature search}

We searched Medline (via PubMed), Chinese Biomedical Literature Database (CBM), Wan Fang Database and Chinese National Knowledge Infrastructure (CNKI) from their inception until November 27, 2020 to identify potentially relevant records. The specific search terms included pancreatic cancer, practice guideline, guidance, and recommendation. We also searched the website of The National Institute for Health and Care Excellence (NICE, https://www.nice.org.uk/), The National Comprehensive Cancer Network (NCCN, https://www.nccn.org/), World Health Organization guidelines (WHO, https:// www.who.int/publications/guidelines/year/en/), Scottish Intercollegiate Guidelines Network (SIGN, https://www. sign.ac.uk/our-guidelines/) and Guidelines International Network (GIN, https://guidelines.ebmportal.com/) as well as Google Scholar to identify additional literature. Language was restricted to Chinese and English.

\section{Inclusion and exclusion criteria}

We included the most recent versions of CPGs focusing on screening, testing, diagnosis, treatment, or management of pancreatic cancer, published between 2018 and 2020, with full-text accessible. We excluded translations, summaries and interpretations of guidelines, as well as draft or unpublished guidelines.

\section{Screening}

CPG selection was performed in two stages. First, titles and abstracts were screened; then, the full texts of potentially relevant articles and related supplementary materials 
were collected to identify eligible CPGs according to the criteria. The selection was performed independently by two authors (MY Sun and XX Chen). Conflicts were settled by consensus, consulting a third reviewer (YF Ma) if necessary.

\section{Data extraction of guidelines}

Data extraction was conducted by two authors independently (XH Ma and YJ Yang). In case of inconsistent interpretation, consensus was reached by consultation with a third author (XJ Zhang). A standardized electronic extraction form was used to obtain the relevant data from each guideline. Extracted data included first author, publication year, publication language, developers, region/country where the CPG was developed, format of publication (peer-reviewed journal, or website only), impact factor (IF) of the journal according to the Science Citation Index (SCI) journal, and the scope/ purpose and target population of the CPG.

\section{Reporting quality assessment using RIGHT checklists}

The RIGHT tool was used to assess the reporting quality of include CPGs. This instrument includes seven domains with a total of 35 items: basic information (six items), background (eight items), evidence (five items), recommendations (seven items), review and quality assurance (two items), funding and conflicts of interest statements and management (four items), and other information (three items). Each of these items was assessed for every guideline independently by two authors (QW Zhang and MM Jia). Disagreements were settled by consulting a third reviewer (JL Lu). The authors performing the assessment were trained by a member of the RIGHT tool working group, and were familiar with the use of this tool. Most items were rated as "Reported" or "Not reported", based on the protocol of RIGHT instrument. "Reported" means that the relevant information was fully reported, whereas "Not reported" means that some relevant information was missing. Items that were not appropriate for evaluation in a specific guideline were assigned as "not applicable".

\section{Statistical analysis}

We report the absolute number and percentage of guidelines reporting each item, and the mean percentages of items reported over all guidelines for the RIGHT checklist overall, and for each domain separately. We also present the mean overall reporting rates stratified by the year of publication, funding support, grading system and format of publication (journal categorized by IF, or website only).

\section{Results}

\section{Identification of guidelines}

Figure 1 shows the flowchart of the search and selection procedure. The electronic searches yielded 1,548 potentially relevant studies, of which 124 duplicate records were excluded. After exclusion of references by the evaluation of title and abstract, we retrieved 35 references for fulltext review. Finally, 22 reports qualified for inclusion in our analysis.

\section{Characteristics of selected guidelines}

Table 1 shows the characteristics of all included CPGs. Five CPGs were published in 2018, seven in 2019, and ten in 2020. Nineteen CPGs were in English, and three in Chinese. Of the 22 guidelines, 14 targeted pancreatic cancer in general, two PDCA exclusively, one chronic pancreatitis, one targeted patients with potentially curable pancreatic cancer, and two targeted individuals with increased risk of pancreatic cancer based on family history or germline mutation status (high-risk individuals). The included guidelines covered a broad range of aspects of pancreatic cancer, including screening, diagnosis, treatment and management. Six CPGs were originally from the United States, four from China, two from Europe (multinational), two from France, and one each from Japan, Poland, Australia, UK and Spain; three guidelines were developed globally. Eleven guidelines were supported by government or institutional funds, and 11 did not report their funding sources.

\section{Analysis of overall reporting quality}

Of the seven domains, the "Background" domain had the highest mean reporting rate of $76.7 \%$; the "Basic information", "Evidence", "Recommendations" and "Other information" domains had also reporting rates greater than $50 \%$ (Figure 2). The reporting rate of "Funding and declaration and management of interests" domain was $43.2 \%$. The "Review and quality assurance" domain had the lowest reporting quality, with a reporting rate of $25.0 \%$.

The mean overall reporting rate was $60 \% ; 17$ of the 35 sub-items were reported by at least $60 \%$ of the 


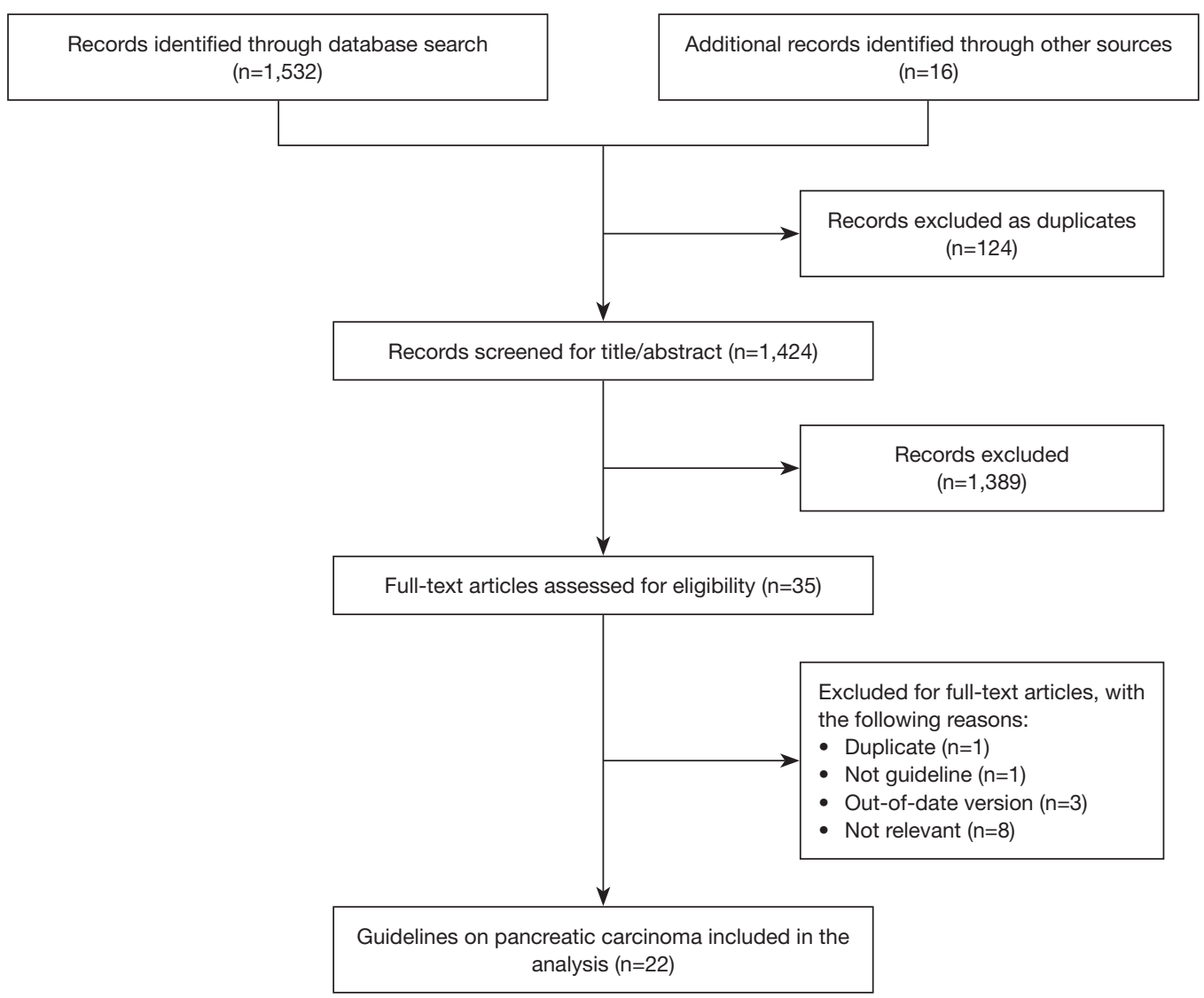

Figure 1 The flow chart of the selection process.

CPGs (Table 2). All guidelines adhered to the items 3 (abbreviations and acronyms), 7a (target population), and 13a (recommendations). No guideline reported the items $14 \mathrm{c}$ (other factors that may affect recommendations) or $18 \mathrm{~b}$ (the role of funders).

Thirteen guidelines had an overall reporting rate above the mean $(>60 \%)$. The two CPGs with the highest reporting rate $(85.7 \%)$ were developed by The American Society of Clinical Oncology (ASCO). The guideline that had the lowest overall reporting rate $(31.4 \%)$ was published in Chinese and developed by the National Clinical Research Center for Radiology and Therapy.

\section{Subgroup analyses of reporting quality}

The mean overall reporting rate was $50.3 \%$ in CPGs published in $2018,67.3 \%$ in 2019 , and $61.1 \%$ in 2020 . We noted a higher reporting proportion in guidelines that were published in journals with IF $\geq 10$ (73.1\%); while guidelines published in Chinese journals were poorly reported (47.6\%).
The reporting quality was better for guidelines using an evidence grading system (69.2\%) compared to $45.7 \%$ for those not using any grading system. Funding support also seemed to influence the reporting quality of the guidelines: reporting proportion was $64.9 \%$ in guidelines with funding support and $56.4 \%$ for those without, or not reporting funding support (Figure 3).

\section{Discussion}

Pancreatic cancer is a highly fatal disease that requires highquality health care to improve survival. Clinical guidelines offer timely clinical recommendations on how to optimize patient management (34). Concerns have been raised that the low quality of reporting guidelines may negatively affect patients. This is to our knowledge the first systematic review of reporting quality in pancreatic cancers guidelines using RIGHT tool.

Most guidelines included in our analysis had several deficiencies in reporting. Items pertaining to the external 
Table 1 Characteristics of eligible CPGs

\begin{tabular}{|c|c|c|c|c|c|c|c|}
\hline No & Year & Country/region & Language & Developer & Grading system & IF & Funding source \\
\hline $2(13)$ & 2020 & Europe & English & ESTRO, ACROP & Unreported & 4.856 & Society \\
\hline $3(14)$ & 2020 & China & Chinese & NCRC-RT, CIMB (CSIP), CIM (CFC) & Unreported & None & Unreported \\
\hline $4(15)$ & 2019 & Japan & English & JPS & GRADE & 2.92 & Society \\
\hline $6(17)$ & 2020 & France & English & INCA & GRADE & 4.848 & Government \\
\hline $7(18)$ & 2019 & Australia & English & AGITG & Unreported & 2.948 & Government \\
\hline $8(19)$ & 2020 & Spain & English & $\begin{array}{l}\text { SEOM, AEC, SEOR, SEEN, SEPD, } \\
\text { SERAM, SEAP }\end{array}$ & GRADE & 2.737 & Society \\
\hline $12(23)$ & 2020 & Global & English & CAPS consortium & Unreported & 19.819 & Government \\
\hline $13(24)$ & 2019 & Poland & English & Working group of PCC & Self-defined & None & Unreported \\
\hline $14(25)$ & 2019 & USA & English & ASTRO & ASTRO & 2.948 & Unreported \\
\hline $15(26)$ & 2019 & USA & English & USPSTF & USPSTF & 45.54 & Government \\
\hline $16(27)$ & 2019 & USA & English & ASCO & GRADE & 32.956 & Society \\
\hline $17(28)$ & 2018 & France & English & $\begin{array}{l}\text { Several French medical and } \\
\text { surgical societies }\end{array}$ & GRADE & 3.57 & Unreported \\
\hline
\end{tabular}

CPGs, clinical practice guidelines; AEC, the Spanish Association of Surgeons; AGITG, The Australasian Gastrointestinal Trials Group; APA, the American Pancreatic Association; ASCO, The American Society of Clinical Oncology; ASTRO, American Society for Radiation Oncology; CAPS, international Cancer of the Pancreas Screening; CIM (CFC), Committee of Interventional Medicine (Cancer Foundation of China); CIMB (CSIP), Committee of Interventional Medicine and Bioengineering (Chinese Society of Interventional Physicians); CPSA (CSS.CMA), Chinese Pancreatic Surgery Association (Chinese Society of Surgery. Chinese Medical Association); CRHA, Chinese Research Hospital Association; EPC, European Pancreatic Club; ESMO, European Society for Medical Oncology; IAP, the International Association of Pancreatology; INCA, The French National Cancer Institute; JPS, Japan Pancreas Society; NCRC-RT, National Clinical Research Center for Radiology and Therapy; NHC of the PRC, The National Health Commission of the People's Republic of China; PCC, the Polish Pancreatic Club; PCCCAA, Pancreatic cancer committee of Chinese anti-cancer association; SEOM, the Spanish Society of Medical Oncology; SEOR, the Spanish Society of Radiation Oncology; SEEN, the Spanish Society of Endocrinology; SEPD, the Spanish Society of Digestive Pathology; SERAM, the Spanish Society of Medical Radiology; SEAP, the Spanish Society of Pathology; USPSTF, US Preventive Services Task Force.

review as well as the funding and declaration and management of interests were poorly reported. In particular, no guideline described the role of funder(s) in the different stages of guideline development and in the dissemination and implementation of the recommendations. The reasons are difficult to ascertain. Both two items contain several 


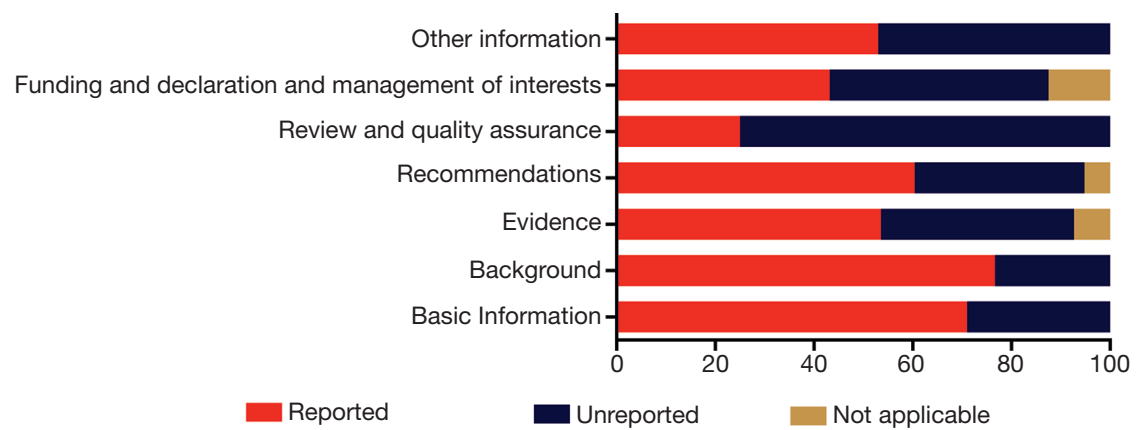

Figure 2 The reporting rates of each RIGHT checklist domain in the included clinical practice guidelines. RIGHT, International Reporting Items for Practice Guidelines in Health Care.

Table 2 The reporting rates of each RIGHT checklist item in the included clinical practice guidelines (11)

\begin{tabular}{|c|c|c|c|c|c|}
\hline Section/topic & No. & Item & $\begin{array}{l}\text { Reported, } \\
\text { n (\%) }\end{array}$ & $\begin{array}{l}\text { Not reported, } \\
\mathrm{n}(\%)\end{array}$ & $\begin{array}{l}\text { Not applicable, } \\
\mathrm{n}(\%)\end{array}$ \\
\hline \multicolumn{6}{|l|}{ Basic Information } \\
\hline Title/subtitle & $1 b$ & Describe the year of publication of the guideline & $7(31.8)$ & $15(68.2)$ & $0(0)$ \\
\hline Executive summary & 2 & $\begin{array}{l}\text { Provide a summary of the recommendations contained in the } \\
\text { guideline }\end{array}$ & $9(40.9)$ & $13(59.1)$ & $0(0)$ \\
\hline $\begin{array}{l}\text { Abbreviations and } \\
\text { acronyms }\end{array}$ & 3 & $\begin{array}{l}\text { Define new or key terms, and provide a list of abbreviations } \\
\text { and acronyms if applicable }\end{array}$ & $22(100.0)$ & $0(0)$ & $0(0)$ \\
\hline \multicolumn{6}{|l|}{ Background } \\
\hline $\begin{array}{l}\text { Brief description of the } \\
\text { health problem(s) }\end{array}$ & 5 & $\begin{array}{l}\text { Describe the basic epidemiology of the problem, such as } \\
\text { the prevalence/incidence, morbidity, mortality, and burden } \\
\text { (including financial) resulting from the problem }\end{array}$ & $21(95.5)$ & $1(4.5)$ & $0(0)$ \\
\hline $\begin{array}{l}\text { Aim(s) of the guideline } \\
\text { and specific objectives }\end{array}$ & 6 & $\begin{array}{l}\text { Describe the aim(s) of the guideline and specific objectives, } \\
\text { such as improvements in health indicators (e.g., mortality and } \\
\text { disease prevalence), quality of life, or cost savings }\end{array}$ & $18(81.8)$ & $4(18.2)$ & $0(0)$ \\
\hline Target population(s) & $7 a$ & $\begin{array}{l}\text { Describe the primary population(s) that is affected by the } \\
\text { recommendation(s) in the guideline }\end{array}$ & $22(100.0)$ & $0(0)$ & $0(0)$ \\
\hline
\end{tabular}

Table 2 (continued) 
Table 2 (continued)

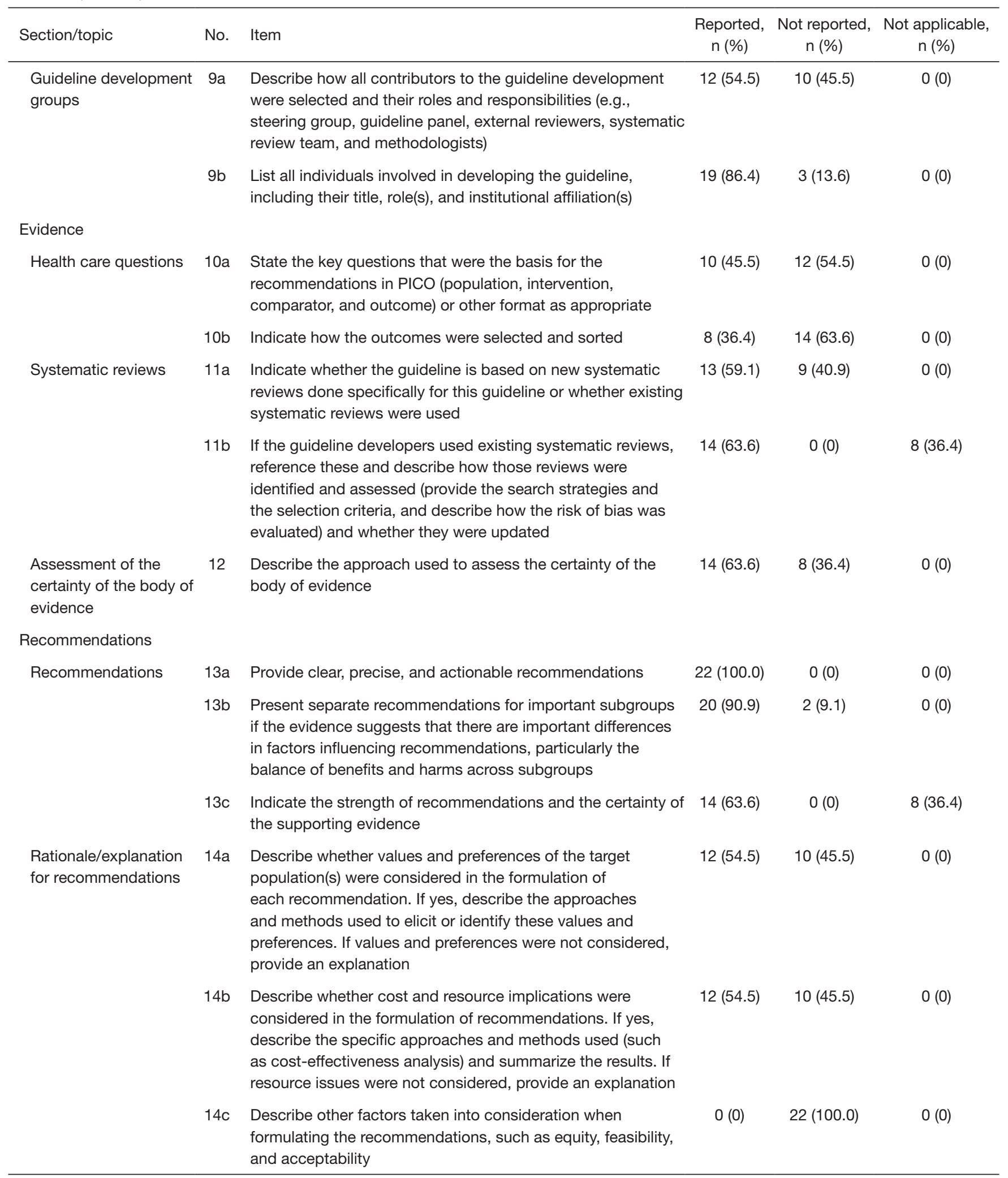

Table 2 (continued) 
Table 2 (continued)

\begin{tabular}{|c|c|c|c|c|c|}
\hline Section/topic & No. & Item & $\begin{array}{l}\text { Reported, } \\
\text { n (\%) }\end{array}$ & $\begin{array}{l}\text { Not reported, } \\
\mathrm{n}(\%)\end{array}$ & $\begin{array}{l}\text { Not applicable, } \\
\mathrm{n}(\%)\end{array}$ \\
\hline $\begin{array}{l}\text { Evidence to decision } \\
\text { processes }\end{array}$ & 15 & $\begin{array}{l}\text { Describe the processes and approaches used by the } \\
\text { guideline development group to make decisions, particularly } \\
\text { the formulation of recommendations (such as how consensus } \\
\text { was defined and achieved and whether voting was used) }\end{array}$ & $13(59.1)$ & $9(40.9)$ & $0(0)$ \\
\hline Quality assurance & 17 & $\begin{array}{l}\text { Indicate whether the guideline was subjected to a quality } \\
\text { assurance process. If yes, describe the process }\end{array}$ & $3(13.6)$ & $19(86.4)$ & $0(0)$ \\
\hline $\begin{array}{l}\text { Funding source(s) and } \\
\text { role(s) of the funder }\end{array}$ & $18 b$ & $\begin{array}{l}\text { Describe the role of funder(s) in the different stages of } \\
\text { guideline development and in the dissemination and } \\
\text { implementation of the recommendations }\end{array}$ & $0(0)$ & $11(50.0)$ & $11(50.0)$ \\
\hline \multirow{2}{*}{$\begin{array}{l}\text { Declaration and } \\
\text { management of } \\
\text { interests }\end{array}$} & $19 a$ & $\begin{array}{l}\text { Describe what types of conflicts (financial and nonfinancial) } \\
\text { were relevant to guideline development }\end{array}$ & $16(72.7)$ & $6(27.3)$ & $0(0)$ \\
\hline & $19 b$ & $\begin{array}{l}\text { Describe how conflicts of interest were evaluated and } \\
\text { managed and how users of the guideline can access the } \\
\text { declarations }\end{array}$ & $11(50.0)$ & $11(50.0)$ & $0(0)$ \\
\hline \multicolumn{6}{|l|}{ Other information } \\
\hline
\end{tabular}

RIGHT, Reporting Items for Practice Guidelines in Healthcare. (Details of the RIGHT checklist is available on: http://www.right-statement. org/right-statement/checklist).

aspects that may have contributed to the reluctance of developers to report them. For example, the funding for CPGs is likely to be primarily used for the publication and dissemination, and the authors may feel that it is not related to the quality of the evidence behind the recommendations, and thus see it unnecessary to report it in detail.

Although the lack of some basic information does not automatically mean that the recommendations are of poor quality, complete and transparent reporting nevertheless facilitates the acceptance and effective use of the guideline. For example, a well-constructed executive summary enables a clear presentation of the different management options and makes key recommendations easily identifiable. The year of publication in the title allows to assess immediately whether the guideline is up-to-date, helping readers find the latest recommendations (35). However, in our analysis, both the year of publication in the title and a summary of recommendations were rarely reported. To ensure 

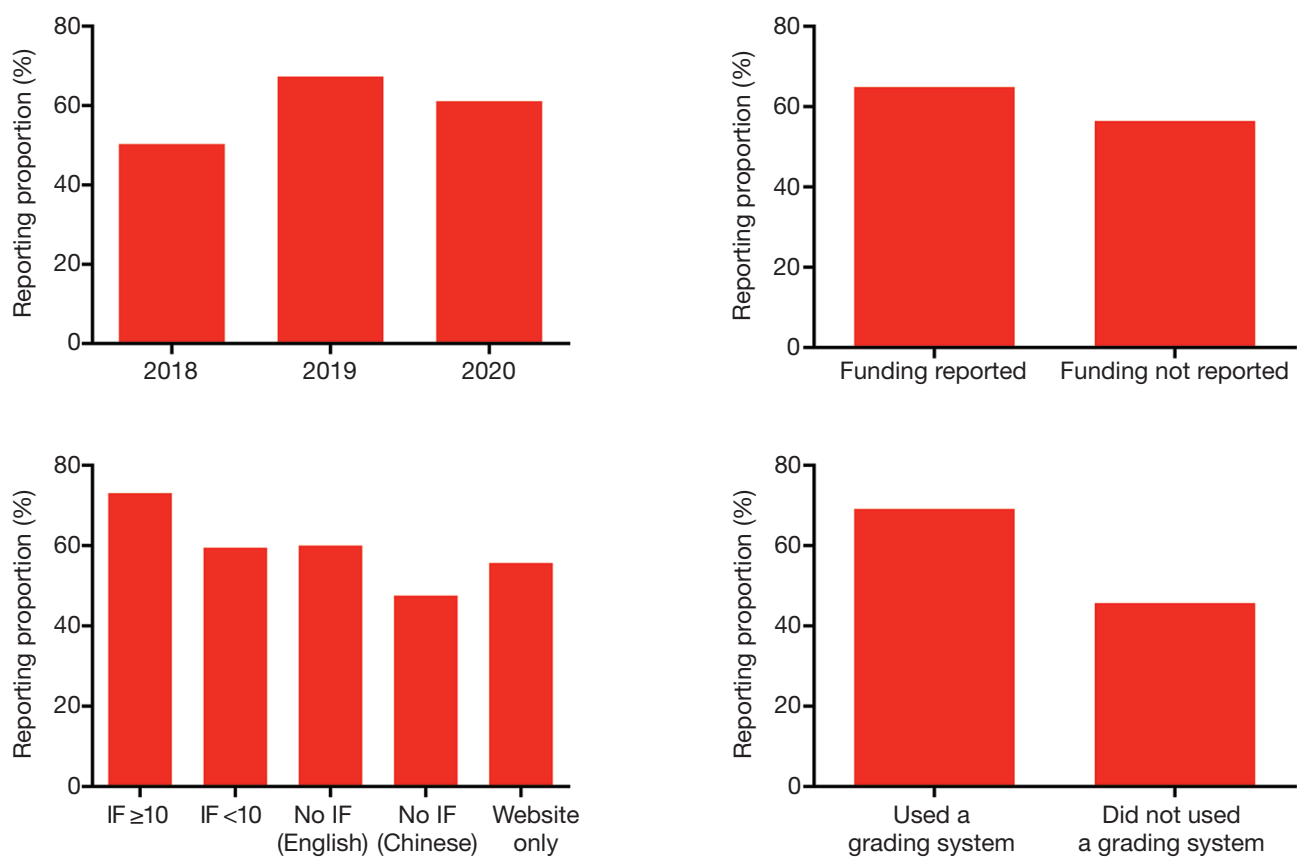

Figure 3 The reporting proportions of included clinical practice guidelines stratified by selected characteristics. IF, impact factor.

high quality, reporting of basic information should not be neglected.

The reporting quality of the "Background" domain tended to be good, except for one item that describes the target setting and facility type of the guideline. The setting should be defined, because a guideline may be applicable only, for example, in selected geographic regions, primary care, or referral facilities. Most guidelines did not report the information about the health care questions the guideline intends to answer. These items of the RIGHT checklist highlight the importance of PICO (patient, intervention, comparison, and outcome) questions, and how the outcomes are selected and sorted. The PICO framework ensures the clinical questions cover the whole scope of the guideline (36). The lack of this information may be one explanation to the variable quality in CPGs.

We did not find any evidence that the overall reporting quality of CPGs for pancreatic cancer would have improved over time. This result may reflect the fact that the RIGHT tool is not yet widely used in the development of guidelines. In fact, the Appraisal of guidelines for research \& evaluation II (AGREE II) instrument, which is a similar tool for methodological quality and was first published in 2010, six years before RIGHT $(37,38)$, was also used infrequently: only one of 22 included CPGs reported the use of this tool for methodological adaptation (15). Therefore, to improve the overall quality of CPGs, the developers should use appropriate tools for guideline reporting and methodology, such as the RIGHT tool and AGREE II.

We found several factors correlating with reporting quality. First, a good quality of guideline reporting was seen in leading journals, which might reflect the transparent and high quality of these journals. Second, we found more complete reporting in guidelines that declared funding support. The reason may be that guideline development is costly and time-consuming, and therefore adequate funding and resources can promote the quality of the guideline (39). Third, the guidelines using evidence grading system such as GRADE presented a better quality in reporting. The use of a grading system may reflect a more comprehensive training or experience in CPG development methodology, which may also improve the quality of reporting.

We acknowledge our study has some limitations. The characteristics of the CPGs were heterogeneous, which may partly explain the observed variations in reporting completeness; thus, the differences between the subgroups we observed may be confounded by a range of other factors. The quality of our analysis is also limited by the inclusion criteria. We only included guidelines that were published in Chinese and English. Inclusion of the Chinese guidelines tended to be poorly reported, decreasing the overall estimates substantially. Therefore, the high proportion 
of English-language guidelines, often published in highimpact scientific journals, may have led to overestimation of the overall reporting quality.

\section{Questions to be further discussed and considered}

Question 1: What impact do you think the low reporting quality of clinical practice guidelines on pancreatic cancer will have on clinicians and clinical practices?

\section{Expert opinion: Dr. Kunibiro Tsuchida}

We think that the low reporting quality of clinical practice guidelines on pancreatic cancer will hinder internationally equal accessibility of clinical data and results. In this manuscript, we report the low reporting rates of "review and quality assurance" and "funding and declaration and management of interests". In some occasions, society and committee are involved in making guidelines. This might be one reason for the low reporting rate of funding and management. Low rate of review and quality assurance is problematic. Guidelines should be reviewed more widely by independent review board, although we understand that standardization of intractable pancreatic cancers is very difficult.

\section{Expert opinion: Dr. Mark Schattner}

Guidelines must always be judicially applied. Unlike "standards of practice" which can be very broadly and often uniformly applied, "guidelines" need to be interpreted to make sure that they are being used in the correct clinical context. For example, they may only be appropriate for one subset of patients with a given disease. It is critical that the guidelines specify how and when they are intended to be used. Lower quality clinical practice guidelines may not recognize and call out this limitation which could result in their use in populations that were not well studied. It is critical that the clinician understand not only what the guidelines recommend but more importantly where the guidelines are intended to be used, the source data for the guidelines, and the inherent limitations of the guidelines. It is only with knowledge of all these factors that the CPG can be correctly applied.

\section{Expert opinion: Dr. Matthew H. G. Katz}

Unfortunately, there is a significant amount of bias in the way patients with pancreatic cancer are managed. That is due to several factors. Data for patients with localized disease is particularly biased because the amount and quality of the data that exist to inform the management of these patients is quite low. Therefore, many decisions are made on the basis of "experiences" and "anecdotes". Without rigorous methodology to the guidelines, management of patients will continue to occur based on preference, bias and experience rather than on data. It is also important to note that existing guidelines to a very poor job of describing value. So patients may be subject to treatments that may improve outcomes statistically but not provide significant value.

\section{Expert opinion: Dr. Salvatore Paiella}

CPGs have been desired because of the general perception that medical assistance could have improved, providing end-users (clinicians) the best and updated scientific knowledge for the best patient's care. On the one side, it is hard for the end-users to ascertain whether the guideline recommendations are trustworthy since the knowledge and the application of the various grading systems are timeconsuming and complex. It is difficult to determine if the low reporting quality of the CPGs found in this manuscript is somehow impactful on managing pancreatic cancer patients. It has been reported that physicians are not prone to incorporate and follow precisely CPGs if they think they are based on opinions or poor evidence or if they are unbalanced toward the physician's point of view (40). It has been reported that adherence to guidelines may positively impact survival, even for pancreatic cancer (41). On the opposite, it may be argued that non-adherence may produce a late diagnosis, an inappropriate treatment, and cost issues. The lowest reporting quality, the highest (apparent) untrustworthiness.

Question 2: What do you think the most important aspects needed for developing high-quality clinical practice guidelines on pancreatic cancer are? Expert opinion: Dr. Kunibiro Tsuchida

Internationally recognized and open guidelines are important for developing high-quality clinical practice guidelines on pancreatic cancers for internationally unified therapies for future. For this purpose, translation in English and availability in other nations are important. For patients, explanation of important aspects of guidelines by clinicians and social workers will be of some help.

\section{Expert opinion: Dr. Mark Schattner}

I think the instruments (such as RIGHT checklist) developed to systemically critique guidelines are critical. These instruments remind a clinician of all of the factors that should be included in a high-quality practice guideline and if reported should allow one to quickly identify high quality clinical practice guidelines. Guidelines should also 
be reviewed and updated on an ongoing basis to make sure that they remain current in this rapidly changing field.

\section{Expert opinion: Dr. Matthew H. G. Katz}

More high quality data is needed. More rigorous methodology in guidelines is necessary. Attention to healthcare value is critical (so what if a drug improves survival by a couple of weeks-erlotinib-what about cost? And descriptions of how guidelines affect certain patient populations. What about low resource patients or settings, for example. Certain drugs or procedures may not be available in every clinical setting, and guidelines need to be tailored to the specific setting-or at least describe limitations of the recommendations in certain situations.

\section{Expert opinion: Dr. Salvatore Paiella}

High-quality CPGs should focus on several aspects; some of them are discussed as follows. First, an irreproachably documented systematic review has to be performed, involving methodologists since the first phase of the production. Second, they should use a grading system to increase trustworthiness. Third, they should include stakeholders and patients. This will ensure proper balancing. Fourth, they should be updated constantly. Fifth, they should have development, dissemination, and implementation strategies. Sixth, they should state the limitations. Seventh, they should receive and convey the feedback of both end-users and patients. Eight, they should have editorial independence and no sponsorship.

\section{Question 3: How do you think conflicts of interest in the guidelines should be handled? Expert opinion: Dr. Kunibiro Tsuchida}

Conflict of interest (COI) is in $19 \mathrm{~b}$. Its reporting rate is $47.8 \%$. Since new drugs such as immune checkpoint inhibitors are becoming available, COI could exist for clinical studies. However, proper management of COI is possible in each hospital and/or medical universities. Declaration of COI is important for clinical studies not only in pancreas cancers but also in other intractable diseases.

\section{Expert opinion: Dr. Mark Schattner}

Conflicts of interest can clearly result in some bias (either intentional or unintentional) in the development and wording of guidelines. It is critical that these conflicts be recognized and any influence they have on the guidelines be minimized. It is also important that these conflicts are completely and accurately reported to the reader so they can develop fully informed opinions about the guidelines.

Expert opinion: Dr. Matthew H. G. Katz

At ASCO, people with conflict of interest are not allowed to participate in development of guidelines. That is important. However, it does not solve all conflict of interest. For example, the ASTRO guidelines, which really only address one methodology, obviously interpret ambiguous clinical data through the lens of individuals who practice in that specialty. Guidelines need to get a broad range of input from providers of different specialties, who practice in different resource settings, to get the most generalizable and accurate recommendations.

\section{Expert opinion: Dr. Salvatore Paiella}

CPGs' Authors commonly report conflicts of interest. A recent systematic review noted that about a half of CPGs claim at least one financial conflict of interest, especially in the oncology field, and that many are undisclosed. Payments included speaking engagements, travel and accommodation expenses coverage, consulting honoraria, research payments, investments, ownership stakes, and royalties (42). Conflicts of interest must be reported for each of the Authors involved, using a separate consultable document. A clear example to follow has been provided by the Association of Scientific Medical Societies in Germany (AWMF) (43).

\section{Conclusions}

In conclusion, the reporting quality of CPGs on pancreatic cancer has remained stable on a suboptimal level over the past three years. The low reporting quality of Chinese-language guidelines was particularly worrying. As adequate reporting is essential for the effective dissemination and implementation of the recommendations, the use of the RIGHT tool should be encouraged when developing CPGs.

\section{Acknowledgments}

The authors appreciate the academic support from the AME Reporting Guideline Collaborative Group.

Funding: This work was supported by the National Science and Technology Major Project of China (grant number 2020ZX09201009).

\section{Footnote}

Conflicts of Interest: All authors have completed the ICMJE uniform disclosure form (available at https://dx.doi. org/10.21037/atm-21-2644). Dr. SP received consulting fee from Consultant Boston Scientific, payment for expert 
testimony from US department of Justice, and participated on a Data Safety Advisory Board of Novo Nordisk. The other authors have no conflicts of interest to declare.

Ethical Statement: The authors are accountable for all aspects of the work in ensuring that questions related to the accuracy or integrity of any part of the work are appropriately investigated and resolved.

Open Access Statement: This is an Open Access article distributed in accordance with the Creative Commons Attribution-NonCommercial-NoDerivs 4.0 International License (CC BY-NC-ND 4.0), which permits the noncommercial replication and distribution of the article with the strict proviso that no changes or edits are made and the original work is properly cited (including links to both the formal publication through the relevant DOI and the license). See: https://creativecommons.org/licenses/by-ncnd $/ 4.0 /$.

\section{References}

1. Bray F, Ferlay J, Soerjomataram I, et al. Global cancer statistics 2018: GLOBOCAN estimates of incidence and mortality worldwide for 36 cancers in 185 countries. CA Cancer J Clin 2018;68:394-424.

2. Howlader N, Noone AM, Krapcho M, et al. SEER Cancer Statistics Review (CSR), 1975-2017, National Cancer Institute (2020). Available online: https://seer. cancer.gov/csr/1975_2017/results_merged/sect_22_ pancreas.pdf

3. Walter FM, Mills K, Mendonca SC, et al. Symptoms and patient factors associated with diagnostic intervals for pancreatic cancer (SYMPTOM pancreatic study): a prospective cohort study. Lancet Gastroenterol Hepatol 2016;1:298-306.

4. Mizrahi JD, Surana R, Valle JW, et al. Pancreatic cancer. Lancet 2020;395:2008-20.

5. Adamska A, Domenichini A, Falasca M. Pancreatic Ductal Adenocarcinoma: Current and Evolving Therapies. Int J Mol Sci 2017;18:1338.

6. Buscail L, Bournet B, Cordelier P. Role of oncogenic KRAS in the diagnosis, prognosis and treatment of pancreatic cancer. Nat Rev Gastroenterol Hepatol 2020;17:153-68.

7. Macherla S, Laks S, Naqash AR, et al. Emerging Role of Immune Checkpoint Blockade in Pancreatic Cancer. Int J Mol Sci 2018;19:3505.
8. Qian Y, Gong Y, Fan Z, et al. Molecular alterations and targeted therapy in pancreatic ductal adenocarcinoma. J Hematol Oncol 2020;13:130.

9. Lambert A, Schwarz L, Borbath I, et al. An update on treatment options for pancreatic adenocarcinoma. Ther Adv Med Oncol 2019;11:1758835919875568.

10. WHO Reginal Office for Europe. Meeting on Guidelines in health care practice, Schloss Velen, Borken, Germany. 26-28 January 1997. Available online: https://www.euro.who.int/__data/assets/pdf_ file/0011/118379/E53492.pdf

11. Chen Y, Yang K, Marusic A, et al. A Reporting Tool for Practice Guidelines in Health Care: The RIGHT Statement. Ann Intern Med 2017;166:128-32.

12. Study Group of Pancreatic Surgery in China Society of Surgery of Chinese Medical Association, Association PDCoCRH. The Guideline for Neoadjuvant Therapy of Pancreatic Cancer in China (2020 Edition) Medical Journal of Peking Union Medical College Hospital 2020;11:547-58.

13. Brunner TB, Haustermans K, Huguet F, et al. ESTRO ACROP guidelines for target volume definition in pancreatic cancer. Radiother Oncol 2021;154:60-9.

14. National Clinical Research Center for Radiology and Therapy, Committee of Interventional Medicine and Bioengineering CSoI-tP, Committee of Interventional Medicine CFoC. Clinical practice guidelines for the interventional treatment of advanced pancreatic carcinoma (on trial) (4th edition) Journal of Clinical Hepatology 2020;36:2188-96.

15. Okusaka T, Nakamura M, Yoshida M, et al. Clinical Practice Guidelines for Pancreatic Cancer 2019 From the Japan Pancreas Society: A Synopsis. Pancreas 2020;49:326-35.

16. Greenhalf W, Lévy P, Gress T, et al. International consensus guidelines on surveillance for pancreatic cancer in chronic pancreatitis. Recommendations from the working group for the international consensus guidelines for chronic pancreatitis in collaboration with the International Association of Pancreatology, the American Pancreatic Association, the Japan Pancreas Society, and European Pancreatic Club. Pancreatology 2020;20:910-8.

17. Delpero JR, Sauvanet A. Vascular Resection for Pancreatic Cancer: 2019 French Recommendations Based on a Literature Review From 2008 to 6-2019. Front Oncol 2020;10:40.

18. Oar A, Lee M, Le H, et al. Australasian Gastrointestinal 
Trials Group (AGITG) and Trans-Tasman Radiation Oncology Group (TROG) Guidelines for Pancreatic Stereotactic Body Radiation Therapy (SBRT). Pract Radiat Oncol 2020;10:e136-46.

19. Martin-Perez E, Dominguez-Munoz JE, Botella-Romero F, et al. Multidisciplinary consensus statement on the clinical management of patients with pancreatic cancer. Clin Transl Oncol 2020;22:1963-75.

20. Sohal DPS, Kennedy EB, Cinar P, et al. Metastatic Pancreatic Cancer: ASCO Guideline Update. J Clin Oncol 2020. [Epub ahead of print]. doi: 10.1200/ JCO.20.01364.

21. Catanese S, Pentheroudakis G, Douillard JY, et al. ESMO Management and treatment adapted recommendations in the COVID-19 era: Pancreatic Cancer. ESMO Open 2020;5:e000804.

22. Stoffel EM, McKernin SE, Brand R, et al. Evaluating Susceptibility to Pancreatic Cancer: ASCO Provisional Clinical Opinion. J Clin Oncol 2019;37:153-64.

23. Goggins M, Overbeek KA, Brand R, et al. Management of patients with increased risk for familial pancreatic cancer: updated recommendations from the International Cancer of the Pancreas Screening (CAPS) Consortium. Gut 2020;69:7-17.

24. Winter K, Talar-Wojnarowska R, Dąbrowski A, et al. Diagnostic and therapeutic recommendations in pancreatic ductal adenocarcinoma. Recommendations of the Working Group of the Polish Pancreatic Club. Prz Gastroenterol 2019;14:1-18.

25. Palta M, Godfrey D, Goodman KA, et al. Radiation Therapy for Pancreatic Cancer: Executive Summary of an ASTRO Clinical Practice Guideline. Pract Radiat Oncol 2019;9:322-32.

26. Owens DK, Davidson KW, Krist AH, et al. Screening for Pancreatic Cancer: US Preventive Services Task Force Reaffirmation Recommendation Statement. JAMA 2019;322:438-44.

27. Khorana AA, McKernin SE, Berlin J, et al. Potentially Curable Pancreatic Adenocarcinoma: ASCO Clinical Practice Guideline Update. J Clin Oncol 2019;37:2082-8.

28. Neuzillet C, Gaujoux S, Williet N, et al. Pancreatic cancer: French clinical practice guidelines for diagnosis, treatment and follow-up (SNFGE, FFCD, GERCOR, UNICANCER, SFCD, SFED, SFRO, ACHBT, AFC). Dig Liver Dis 2018;50:1257-71.

29. Drewes AM, Campbell CM, Ceyhan GO, et al. Pain in pancreatic ductal adenocarcinoma: A multidisciplinary,
International guideline for optimized management. Pancreatology 2018;18:446-57.

30. Association PCCoCA-C. Comprehensive guidelines for the diagnosis and treatment of pancreatic cancer(2018 version). Chinese Journal of Surgery 2018;56:481-94.

31. National Health Commission Of The People's Republic Of C. Chinese guidelines for diagnosis and treatment of pancreatic cancer 2018 (English version). Chin J Cancer Res 2019;31:278-94.

32. NICE. Pancreatic cancer in adults: diagnosis and management. Available online: https://www.nice.org.uk/ guidance/ng85

33. Tempero MA, Malafa MP, Al-Hawary M, et al. Pancreatic Adenocarcinoma, Version 1.2021. Available online: https:// www.nccn.org/

34. Brouwers MC, Florez ID, McNair SA, et al. Clinical Practice Guidelines: Tools to Support High Quality Patient Care. Semin Nucl Med 2019;49:145-52.

35. Kredo T, Bernhardsson S, Machingaidze S, et al. Guide to clinical practice guidelines: the current state of play. Int J Qual Health Care 2016;28:122-8.

36. Rosenfeld RM, Shiffman RN. Clinical practice guideline development manual: a quality-driven approach for translating evidence into action. Otolaryngol Head Neck Surg 2009;140:S1-43.

37. Brouwers MC, Kho ME, Browman GP, et al. AGREE II: advancing guideline development, reporting and evaluation in health care. CMAJ 2010;182:E839-42.

38. Brouwers MC, Kerkvliet K, Spithoff K. The AGREE Reporting Checklist: a tool to improve reporting of clinical practice guidelines. BMJ 2016;352:i1152.

39. McCaul M, Ernstzen D, Temmingh H, et al. Clinical practice guideline adaptation methods in resourceconstrained settings: four case studies from South Africa. BMJ Evid Based Med 2020;25:193-8.

40. Heneghan C, Perera R, Mant D, et al. Hypertension guideline recommendations in general practice: awareness, agreement, adoption, and adherence. Br J Gen Pract 2007;57:948-52.

41. Abrams RA, Winter KA, Regine WF, et al. Failure to adhere to protocol specified radiation therapy guidelines was associated with decreased survival in RTOG 9704--a phase III trial of adjuvant chemotherapy and chemoradiotherapy for patients with resected adenocarcinoma of the pancreas. Int J Radiat Oncol Biol Phys 2012;82:809-16.

42. Tabatabavakili S, Khan R, Scaffidi MA, et al. Financial Conflicts of Interest in Clinical Practice Guidelines: A 
Systematic Review. Mayo Clin Proc Innov Qual Outcomes 2021;5:466-75.

43. Schott G, Lieb K, Konig J, et al. Declaration and
Handling of Conflicts of Interest in Guidelines: A Study of S1 Guidelines From German Specialist Societies From 2010-2013. Dtsch Arztebl Int 2015;112:445-51.
Cite this article as: Zhang Q, Lu J, Jia M, Ma Y, Sun M, Chen X, Ma X, Yang Y, Kang J, Zhang X, Paiella S, Katz MHG, Tsuchida K, Schattner M, Du S. Evaluation of the reporting quality of clinical practice guidelines on pancreatic cancer using the RIGHT checklist. Ann Transl Med 2021;9(13):1088. doi: 10.21037/atm-21-2644 